\title{
MENINGKATKAN MINAT BELAJAR SISWA TUNARUNGU DENGAN E-CASH MATEMATIKA DI SMK NEGERI 3 PROBOLINGGO
}

\author{
Dwi Anggraeni \\ SMK Negeri 3 Probolinggo, Jawa Timur \\ Email: e2n1almira@gmail.com
}

\begin{abstract}
Abstrak
Matematika adalah bahasa simbol karena matematika terdiri dari simbol-simbol yang padat arti dan berlaku secara universal (umum). Matematika merupakan pelajaran yang wajib diberikan pada semua siswa pada tiap jenjang pendidikan, termasuk siswa tunarungu yang berada pada pendidikan inklusi. Berdasarkan gaya belajar siswa Tunarungu yang visual, guru menyajikan pembelajaran Matematika dengan menggunakan media E-CASH (Exploration Calculator Sheets). Bahasa Matematika yang disajikan dengan KeyLog pada kalkulator sebagai visualisasi prosedur dan penyajian masalah Matematika " $w 1 w 515=z 6=12=3=4=12====$ ”. Penyajian instruksi Matematika menggunakan KeyLog dapat digunakan sebagai pengganti bahasa lisan guru terhadap siswa Tunarungu dalam memberikan materi persamaan linear dan materi lainnya, sehingga siswa dapat memahami apa yang disajikan guru di kelas secara klasikal (siswa ABK dan reguler) dan untuk memberikan keterampilan mengoperasikan/prosedur Matematika secara tepat. Hasil yang dicapai dari kegiatan pembelajaran matematika pada pendidikan inklusif SMK Negeri 3 Probolinggo dengan menggunakan E-CASH menunjukkan bahwa minat siswa secara signifikan meningkat dilihat dari aktivitas siswa mengikuti pelajaran Matematika, keterlibatan siswa, ketertarikan siswa akan pelajaran Matematika, dan perhatian siswa pada saat proses pembelajaran meningkat dari 40,28\% menjadi $68,54 \%$. Hasil pengamatan juga menunjukkan bahwa aktivitas pembelajaran di kelas mulai bergeser dari teacher centred ke student centred dan kelas menjadi lebih kondusif.
\end{abstract}

Kata kunci: E-CASH, Minat, siswa Tunarungu, student centred.

\begin{abstract}
Mathematics is a language of symbols because mathematics consists of symbols that are densely meaningful and universally applicable. Mathematics is a compulsory subject for all students at every level of education, including hearing impaired students in inclusive education. Based on the visual learning style of hearing impaired students, teacher can present Mathematics learning using E-CASH (Exploration Calculator Sheets) media. Mathematical language is presented with the KeyLog on the calculator as a visualization of the procedure and presentation of Mathematical problems "w1w515 $=z 6=12=3=4=12===="$. Presentation of Mathematics instruction uses KeyLog as a substitute for the teacher's verbal language to hearing impaired students in providing material in linear equations and other material, so students can understand what the teacher is presenting in class classically (ABK and regular students) and to provide appropriate Math operating / procedural skills. The results achieved from mathematics learning activities in inclusive education of SMK Negeri 3 Probolinggo by using E-CASH showed that student interest is significantly increased from student activities following Mathematics, student involvement, student interest in Mathematics, and student
\end{abstract}


attention during the learning process increased from $40.28 \%$ to $68.54 \%$. The observations also showed that learning activities in the class began to shift from teacher centered to student centered and the class became more conducive.

Keywords: E-CASH, interest, hearing impaired students, student centered.

\section{PENDAHULUAN}

Sekolah Menengah Kejuruan (SMK) Negeri 3, sebagai penyelenggara pendidikan inklusif, memiliki kewajiban menampung semua siswa termasuk siswa atau anak berkebutuhan khusus (ABK) dengan mendapatkan layanan yang berbeda sesuai kemampuan dan kebutuhan siswa. Dengan adanya siswa reguler dan siswa ABK dalam satu kelas bersama, maka layanan dalam kelas pun akan berbeda antara keduanya termasuk pelaksanaan kurikulumnya. Untuk layanan khusus yang berlaku bagi siswa ABK, kurikulum dimodifikasi sesuai dengan kebutuhannya sedangkan siswa reguler melaksanakan kurikulum yang berlaku. Demikian halnya dengan perangkat yang dimiliki, guru juga harus menyediakan perencanaan pembelajaran yang dimodifikasi sesuai dengan kebutuhan siswa ABK dari perencanaan pembelajaran umum yang dibuat.

Siswa tunarungu adalah siswa ABK dengan gangguan pendengaran yang mengalami kekurangan atau kehilangan kemampuan mendengar baik sebagian atau seluruhnya yang diakibatkan tidak berfungsinya sebagian atau seluruh alat pendengaran, sehingga tidak dapat menggunakan alat pendengarannya dalam kehidupan sehari-hari (Hasan, Handayani, \& Psych, 2014; Mansell, 2010; Nakken \&Vlaskamp ,2007; Poppes, Van der Putten, \& Vlaskamp, 2010; Winarsih, 2007; Wuwungan, 2016). Sebagai dampak ketunarunguan akan berpengaruh dan kesulitan bicara, hal tersebut berakibat pada tidak optimalnya dalam memahami konsep bacaan setiap materi pelajaran karena minimnya kosakata yang berakhir pada kesulitan dalam menangkap konsep pelajaran termasuk pelajaran matematika. Kondisi tersebut berdampak luas pada intelegensi dan kemampuan kognitif yang berakibat pada rendahnya minat belajar siswa tunarungu (Rahman, Aryani, \& Sinring, 2019; Weismann, Tolla, \& Sinring, 2018).

Objek matematika adalah benda pikiran yang sifatnya abstrak dan tidak dapat diamati dengan panca indra (Hernadi, 2008; Ratumanan \& Laurens, 2016; Wahbi \& Bey, 2017). Oleh karena itu, wajar jika matematika tidak mudah dipahami dan disenangi oleh kebanyakan siswa apalagi siswa tunarungu dengan karakteristik yang dimiliki. Untuk itu dalam mengajarkan suatu konsep/prinsip-prinsip matematika dibutuhkan pengalaman melalui benda-benda nyata (kongkret), yaitu media/alat peraga yang dapat digunakan sebagai jembatan bagi siswa untuk berpikir abstrak dan komunikasi matematika.

Bagaimana guru mata pelajaran matematika menyajikan matematika sebagai pelajaran yang penting dalam hidupnya dan siswa tunarungu dapat memahami apa yang disampaikan penulis dari setiap penjelasan yang disajikan secara klasikal di kelas inklusif dengan keterbatasan pendengaran, bahasa, intelegensi dan kemampuan kognitif agar dapat belajar bersama siswa reguler lainnya? Sebagaimana yang disampaikan oleh para pakar (Dewayani, 2016; Malatista \& Sediyono, 2012; Salim, 2015) bahwa pengajaran anak tunarungu harus mempertimbangkan tentang bagaimana merehabilitasi pendengarannya, mengembangkan komunikasinya, dan mengembangkan dan menata pendidikannya. 
Dari ketiga hal tersebut, salah satu upaya yang dapat dikembangkan dalam pembelajaran matematika adalah mengembangkan komunikasi siswa tunarungu dengan menggunakan E-CASH (Exploration Calculator Sheets) sebagai bahasa pengantar matematika agar siswa memahami materi matematika secara visual. Dengan demikian, studi mengenai minat belajar siswa tunarungu dengan E-CASH Matematika di SMK 3 Probolinggo ini menggunakan pendekatan deskriptif-kualitatif (persentase) dalam mengamati dan menjelaskan proses dan melaporkan hasilnya.

\section{PEMBAHASAN}

Sejumlah pakar (Ahmadi \& Supriyono, 2013; Booth \& Ainscow, 2002; Mardiana, 2016; Moores, 2001; Winarsih, 2007) sependapat bahwa wajibnya matematika diajarkan dan hasil psikotes siswa tunarungu yang menyatakan bahwa kemampuan numeriknya dapat dikembangkan dan anak adalah seorang makhluk manusia yang memerlukan pendidikan (homo educandum) dan dapat dididik (homo educable). Sebagai akibat dari kondisi yang memerlukan layanan khusus, dan sebagai pribadi yang unik memiliki karakteristik minat, kemampuan dan kebutuhan yang berbeda, maka penulis menyajikan pembelajaran matematika secara visual sesuai gaya belajar siswa tunarungu dengan menggunakan E-CASH (Exploration Calculator Sheet) Casio FX-991 ID Plus.

Strategi pemecahan masalah yang dilakukan dalam memberikan layanan pendidikan bagi siswa ABK yang berada di lingkungan sekolah reguler harus memahami kondisi siswa secara detail termasuk dengan melihat catatan kesehatannya. Selanjutnya penyelesaian masalah dalam matematika, penulis melakukan pembelajaran dengan menyajikan worksheets sebagai media komunikasi berbantukan KeyLog calculator Casio Fx-991 ID Plus sebagai panduan siswa tunarungu dalam memanfaatkan media calculator. Berikut bentuk sajian worksheets yang disajikan sebagai prosedur yang harus diikuti oleh siswa tunarungu untuk menyelesaikan permasalahan matematika:

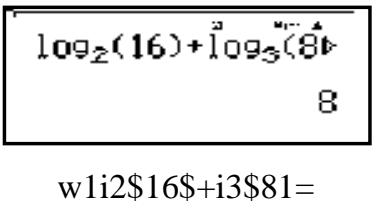

Gambar 1. Gambar Tampilan Casio FX-991 ID Plus sebagai media Bantu Matematika (atas) dan KeyLog sebagai langkah menggunakan kalkulator dalam penyelesaian masalah (bawah) Dengan menyajikan soal dan diikuti cara memanfaatkan calculator Casio FX-991 ID Plus, siswa dengan sendirinya akan melakukan explorasi dengan mengingat apa saja yang harus ditekan untuk menemukan mode menyelesaikan soal matematika yang disajikan. Kegiatan ini dilakukan berulangulang untuk membiasakan peserta didik mengingat dan terampil mengenal mode dan fitur yang ada di calculator Casio FX-991 ID Plus untuk berbagai materi yang disajikan, selanjutnya worksheets yang disajikan tidak lagi disertai KeyLog sebagai petunjuk kerja/prosedur, agar daya ingat dan literasi matematika mereka lebih kuat.

\section{Contoh soal:}

1) Tentukan nilai $x_{1}$ dan $x_{2}$ dari persamaan kuadrat $2 x^{2}+5 x-8=0$, bagaimana menyampaikan bahasa matematika kepada siswa tunarungu baik dari guru pengajar dan siswa sebagai tutor sebaya? 


\section{Jawab:}

Yaitu dengan menunjukkan proses dan prosedur pada penggunaan kalkulatornya dengan menekan angka dan variabel yang dimaksudkan sebagai bahasa komunikasinya:

“w532Q)d=Cw5532Q) $\mathrm{d}=5 \mathrm{Q}$ ) $=\mathrm{z} 8======2=5=\mathrm{z} 8====="$ diperoleh tampilan fitur bertahap berikut:

$1: \operatorname{an} X+\operatorname{bn} Y=c \cdot n$

2: $\operatorname{an} X+\operatorname{bin} \gamma+\operatorname{con} Z=d r$

3: $a \times 2+b \times+c=0$

4: $a \times 3+b \times 2+c \times+d=0$
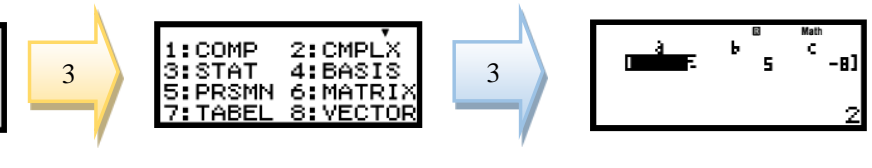
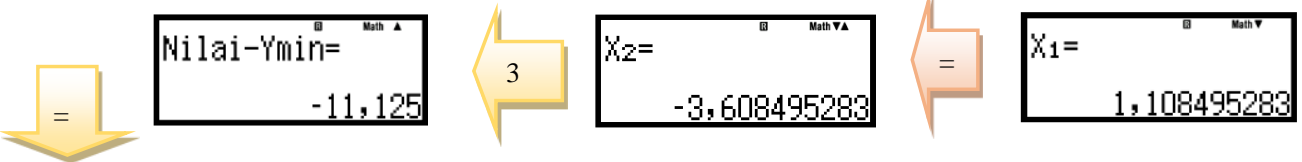

Milai-Xminin=

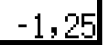

2) Tentukan nilai $A+B$, jika $A=\left[\begin{array}{ccc}2 & 7 & -4 \\ -3 & 5 & 9 \\ 6 & 8 & 3\end{array}\right], B=\left[\begin{array}{ccc}-2 & 5 & 10 \\ 3 & -5 & -7 \\ 7 & 2 & 4\end{array}\right]$ adalah...

(selesaikan dengan menggunakan kalkulator fx-991 ID Plus w6)

\section{Jawab:}

w6112=7=z4=z3=5=9=6=8=3=Cw621 z2=5=10=3=z5=z7=7=2=4=Cq43+q44=

(sebagai bahasa komunikasi matematika dan prosedur) dan hasilnya adalah sebagai berikut:

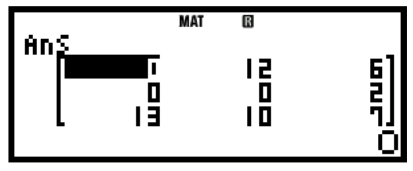

3) Tentukan nilai rata-rata data berikut 2, 3, 4, 4, 5, 6, 6, 7, 8, 8, 8, 9, 10 kemudian tentukan nilai simpangan kuartil data tersebut!

Jawab: peserta didik tunarungu menyiapkan media kalkulator dan melakukan prosedur sebagai berikut:

Tekanlah tombol yang tertera dalam calculator berikut ini (disajikan dalam emulator sebagai petunjuk menggunakannya):

w $312=3=4=4=5=6=6=7=8=8=8=9=10=$

Selanjutnya lakukan tahap berikutnya dengan mengikuti prosedur menggunakan calculator:

Menentukan nilai rata-rata, tekan tombol berikut: $\mathrm{Cq} 142=$

Dengan hasil yang diperoleh dari tampilan tersebut adalah: 


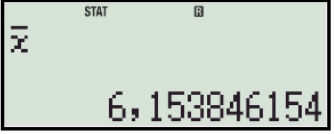

Selanjutnya siswa menentukan simpangan kuartil dari data tersebut, dengan mengikuti perintah menekan tombol berikut untuk literasi:

Cq165pq163)!!!!(\$\$\$P2=

Dan hasil yang diperoleh dari proses tersebut simpangan kuartilnya adalah:

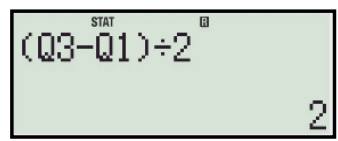

Prosedur ini dapat dilakukan dengan menentukan ukuran pemusatan lainnya dengan soal yang berbeda dan data yang ditentukan adalah data tunggal dan tunggal berbobot. Setiap strategi pemecahan masalah akan timbul masalah baru yang juga harus segera diselesaikan penulis agar layanan pendidikan inklusif bisa berjalan dengan baik. Saat $E$ - $C A S H$ dibuat dan siswa menggunakan media Calculator Casio FX-991 ID Plus untuk menemukan penyelesaian matematika yang disajikan, sarana harus tersedia sejumlah peserta didik dalam kelas. Saat permasalahan ini muncul, penulis mencoba melakukan hal yang sederhana dengan merekam semua kegiatan pembelajaran matematika di kelas selanjutnya. Rekaman diunggah di Youtube dan dishare ke beberapa grup master trainer Casio P4TK (Pusat Pengembangan dan Pemberdayaan Pendidikan dan Tenaga Kependidikan) Matematika Yogyakarta dan Casio For Education Indonesia melalui media sosial whatsapp. Kegiatan merekam ini dilakukan berulang-ulang sampai pada rekaman kemampuan siswa tunarungu terbaca melalui pengamatan hasil rekaman video dan proses belajar di kelas meningkat minat belajarnya, termasuk kegiatan/aktivitas siswa berbagi dengan teman sejawatnya. Ada beberapa langkah yang dilakukan penulis sebelum pemilihan media dan bahan ajar E-CASH dengan menggunakan kalkulator saintifik, yaitu:

1. Melakukan komunikasi ringan dengan melakukan pendekatan secara personal agar siswa tunarungu merasa nyaman dan tidak merasa takut dengan kehadiran penulis.

2. Mengidentifikasi jenis ketunaan yang disandang siswa dengan bantuan informasi yang diperoleh dari Guru Pendamping Khusus (GPK) di sekolah atau guru Bimbingan Konseling dan menganalisis kebutuhan siswa Tunarungu.

3. Menganalisis Materi, Standar Kompetensi/Kompetensi Dasar (SK/KD) Kelas XII,

4. Menyusun media berupa worksheets Matematika berbantukan Calculator Casio FX-991 ID Plus yang disebut dengan E-CASH Matematika.

5. Melakukan ujicoba pada peserta didik reguler dan siswa tunarungu dengan pendampingan dan pembimbingan dalam memahami bahan worksheets sebagai media explorasi matematika dengan pendampingan teman sebaya dan pendampingan guru dalam bentuk layanan khusus. Selanjutnya E-CASH digunakan untuk pembelajaran matematika siswa tunarungu.

Langkah selanjutnya adalah membuat media E-CASH yang dapat digunakan untuk seluruh peserta didik dalam kelas dalam menyelesaikan permasalahan matematika sesuai prosedur. Langkah-langkah 
tersebut dituangkan dalam Rencana Pelaksanaan Pembelajaran (RPP) yang dimodifikasi tanpa harus melaksanakan kurikulum khusus untuk pendidikan inklusif. Dengan demikian, peserta didik tunarungu dapat belajar bersama sejajar dengan peserta didik reguler lainnya dan proses pembelajaran lebih efektif dengan menggunakan media kalkulator FX-991 ID Plus.

Untuk meningkatkan keterampilan menyelesaikan masalah matematika, Dandi dan Husein diberikan kegiatan bimbingan di luar jam pembelajaran ataupun di sela-sela jam istirahat dimana mereka tidak melakukan aktivitas belajar lainnya dengan soal-soal yang berbeda dari beberapa materi termasuk materi yang disiapkan untuk latihan USBN dan UNBK. Memberikan bantuan seperlunya juga dilakukan pada siswa agar siswa tetap dijaga kemandiriannya dan tidak bergantung penuh pada guru, hal ini salah satu bentuk penguatan karakter siswa inklusi membentuk rasa percaya diri dan keingintahuannya.

\section{HASIL YANG DICAPAI}

Pengertian minat menurut Slameto (2010) adalah suatu keadaan dimana ada rasa lebih suka dan rasa keterikatan pada suatu aktivitas tanpa ada yang memerintahkan untuk melakukan. Minat tersebut akan bisa menjadi besar saat hubungan tersebut semakin kuat dan dekat baik dipaksa ataupun tidak dipaksa. Untuk mengukur seberapa besar minat yang dimiliki, indikator yang mendukung adalah: (1) Perasaan senang, apabila siswa memiliki perasaan senang terhadap pelajaran tertentu maka tidak akan ada rasa terpaksa untuk belajar. Contohnya: senang mengikuti pelajaran, tidak ada perasaan terpaksa/ bosan dan selalu hadir pada setiap pelajaran; (2) Keterlibatan Siswa, keterlibatan seseorang akan obyek yang menyebabkan orang tersebut senang dan tertarik untuk melakukan atau mengerjakan kegiatan dari obyek tersebut. Contoh: aktif dalam diskusi, aktif bertanya, aktif menjawab/ presentasi; (3) Ketertarikan, berhubungan dengan daya dorong siswa terhadap ketertarikan pada suatu benda, orang, kegiatan atau pengalaman efektif yang dirancang oleh kegiatan itu sendiri. Contoh: antusias dalam mengikuti pelajaran, tidak menunda tugas dari guru; (4) Perhatian siswa, minat dan perhatian merupakan dua hal yang dianggap sama dalam hal penggunaan sehari-hari, perhatian siswa merupakan konsentrasi siswa terhadap pengamatan dan pengertian, dengan mengesampingkan yang lain. Siswa memiliki minat pada obyek tertentu maka dengan sendirinya akan memperhatikan obyek tersebut. Contoh: mendengarkan penjelasan guru dan mencatat materi.

Mengacu pada latar belakang masalah, langkah-langkah pemecahan masalah, hambatan dan solusinya yang selanjutnya dikaitkan dengan hasil yang terjadi di lapangan berdasarkan pengamatan kegiatan belajar siswa dan angket, maka diperoleh hasil seperti pada tabel 1 dan 2.

Tabel 1. Deskripsi Hasil Pengamatan Proses Pembelajaran di Kelas XII DKV

\begin{tabular}{lll}
\hline \multicolumn{1}{c}{ Indikator Pengamatan } & \multicolumn{1}{c}{ Sebelum } & \multicolumn{1}{c}{ Sesudah } \\
\hline Kondisi Kelas & Kurang Kondusif & Kondusif \\
\hline Konsentrasi Belajar & Kurang & Cukup \\
\hline Bertanya & Tidak aktif & Aktif \\
\hline Keinginan Mempresentasikan & Menunggu ditunjuk & $\begin{array}{l}\text { Keinginan sendiri } \\
\text { Hasil }\end{array}$ \\
\hline
\end{tabular}




\begin{tabular}{lll}
\hline \multicolumn{1}{c}{ Indikator Pengamatan } & \multicolumn{1}{c}{ Sebelum } & \multicolumn{1}{c}{ Sesudah } \\
\hline $\begin{array}{l}\text { Mengajukan Pertanyaan dan } \\
\text { Menjawab }\end{array}$ & Pasif & Aktif \\
\hline Kemampuan berdiskusi & $\begin{array}{l}\text { Pasif, siswa tertentu yang } \\
\text { aktif dan lainnya hanya } \\
\text { mengikuti hasil diskusi } \\
\text { dengan diam, bicara dengan } \\
\text { teman sekelompok. }\end{array}$ & $\begin{array}{l}\text { Aktif, beberapa siswa mulai } \\
\text { menjadi mediator pemecahan } \\
\text { masalah antar kelompok, ada } \\
\text { siswa dalam kelompok belum } \\
\text { fokus dan berbicara dengan } \\
\text { kelompok lainnya. }\end{array}$ \\
& $\begin{array}{ll}12,5 \% \text { kurang tepat waktu } \\
\text { dari 32 siswa }\end{array}$ \\
\hline Aktifitas Menyelesaikan tugas & $25 \%$ Kurang tepat waktu dari & \\
& 32 siswa &
\end{tabular}

Tabel 2. Hasil Minat Belajar Matematika dengan Menggunakan Casio FX-991 ID Plus

\begin{tabular}{lcc}
\hline \multicolumn{1}{c}{ Indikator Minat Belajar } & Sebelum & Sesudah \\
\hline Senang Mengikuti Pelajaran & $46,88 \%$ & $65,63 \%$ \\
\hline Kehadiran siswa saat pelajaran & $78,13 \%$ & $93,75 \%$ \\
\hline Keaktifan dalam diskusi kelompok & $43,75 \%$ & $65,63 \%$ \\
\hline Aktivitas bertanya & $31,25 \%$ & $56,25 \%$ \\
\hline Aktivitas menjawab/ presentasi & $15,63 \%$ & $50 \%$ \\
\hline Aktif mengikuti pelajaran & $71,88 \%$ & $90 \%$ \\
\hline Tugas dikerjakan tepat waktunya & $25 \%$ & $81,25 \%$ \\
\hline Konsentrasi mendengarkan penjelasan guru & $25 \%$ & $78,13 \%$ \\
\hline Siswa Mencatat materi yang disampaikan guru & $25 \%$ & $81,25 \%$ \\
\hline Total Capaian Aktivitas & $\mathbf{4 0 , 2 8 \%}$ & $\mathbf{6 8 , 5 4 \%}$ \\
\hline
\end{tabular}

Hasil yang diperoleh dari pembelajaran $E$ - $C A S H$ matematika lebih bersemangat dan berminat belajar matematika dari 40,28\% menjadi 68,54\% untuk total capaian aktivitas pembelajaran matematika, demikian halnya dengan Dandi dan Husein (siswa Tunarungu) sudah mampu menyelesaikan soal matematika dari latihan soal Ujian Nasional, USBN, dan tryout dengan menggunakan media kalkulator saintifik, bahkan mereka berdua mampu menjadi fasilitator bagi teman-teman sejawatnya dalam menyelesaikan soal matematika meskipun mereka harus menggunakan calculator Casio FX991 ID Plus dalam menjelaskan pada teman-temannya. Rasa bangga pada dirinya mampu menjadikan mereka duduk sejajar dengan teman regular lainnya dan meningkatkan minat belajar matematika untuk selanjutnya. Dandi dan Husein sudah mampu membantu penulis menjadi asisten guru untuk mengajarkan bagaimana menyelesaikan soal-soal matematika bisa diselesaikan dengan menggunakan calculator Casio FX-991 ID Plus, teman sebaya membantu memantapkan konsep berpikir dengan menggunakan jam pelajaran di ruang layanan konseling belajar inklusi dan pada saat kegiatan seminar inklusi mereka juga tidak malu dan dengan bangga mereka mampu membantu guru matematika/guru 
pendamping khusus untuk mengoperasikan calculator Casio FX-991 ID Plus saintific dalam menyelesaikan masalah yang disajikan.

Akan tetapi dari hasil nilai ujian nasional siswa tunarungu belum memenuhi Kriteria Ketuntasan Minimal (KKM) yang ditetapkan secara regular, hal ini disebabkan siswa Tunarungu memiliki keterbatasan dalam segi kognitif karena hambatan bahasanya dari keterbatasan pendengarannya (Fitriawan 2016; Mardiana 2016; Patmawijayanti 2016). Namun mereka memiliki keistimewaan dalam keterampilan life skill, keterampilan motorik dan kemampuan mengingat apa yang pernah dilakukan. Keistimewaan inilah yang menjadi celah yang dapat penulis kembangkan untuk membekalinya keterampilan memecahkan masalah Matematika dengan menggunakan media kalkulator saintifik.

Pembelajaran matematika dengan menggunakan E-CASH berbantukan Calculator Casio FX-991 ID Plus di SMKN 3 Probolinggo sesuai tujuan penyelenggaraan SMK telah mencetak tenaga kerja muda mandiri yang mampu menghadapi real life di beberapa bidang pekerjaan dengan bekal keterampilan yang dimilikinya, misalnya: Husein dengan karakter dan ketunaan yang disandangnya mampu melakukan beberapa aktivitas yang lebih. Husein mampu mengambil posisi pekerjaannya sebagai guru matematika di Sekolah Luar Biasa (SLB) atau membuka lapangan pekerjaan dengan memberikan bimbingan belajar matematika dengan menggunakan media yang dikuasainya bagi siswa berkebutuhan khusus. Lain halnya dengan Dandi sang atlet renang, dengan kemampuan dan bakat yang dimilikinya dia mampu mengambil posisi pekerjaan yang sama dengan Husein bahkan melanjutkan ke perguruan tinggi sesuai kemampuan yang dimilikinya termasuk membuka peluang usaha. Termasuk Ranti dan Yanti dalam kegiatan selanjutnya setelah lulus sekolah telah membuka usaha mandiri dengan mengembangkan keterampilan yang dimilikinya.

\section{KESIMPULAN DAN SARAN}

Siswa tunarungu menjadi bagian dari komunitas pendidikan inklusif yang mendapat pelayanan sama dengan siswa reguler lainnya. Peran serta orangtua, guru dan lingkungan menjadi motivasi tersendiri bagi siswa tunarungu untuk tumbuh kembang menjadi generasi yang siap menghadapi masa depannya dengan percaya diri. Demikian pula, guru mampu menciptakan pembelajaran yang menyenangkan bagi mereka dan menyiapkan perangkat pembelajaran yang sesuai kebutuhan siswa tunarungu tanpa mengabaikan kebutuhan siswa reguler, salah satunya adalah menyiapkan bahan ajar dan media yang dapat digunakan dalam menyampaikan materi pelajaran. Dalam hal ini $E$ - $C A S H$ matematika menjadi salah satu solusi media sakaligus bahan ajar yang dapat melibatkan siswa tunarungu belajar matematika dan meningkatkan minat belajar matematika yang pada dasarnya siswa Tunarungu memiliki IQ (Intelligence Quotion) rata-rata dan dapat mengikuti pembelajaran di sekolah inklusi jika penanganan gurunya dengan menggunakan strategi pembelajaran dan tepat media serta dilakukan secara kontinu.

Melihat aktivitas peserta didik Tunarungu yang lebih nyaman belajar Matematika dengan menggunakan alat bantu kalkulator dan sebagai pengembangannya guru menyiapkan worksheets yang mendukung eksplorasi siswa ( $E-C A S H)$ untuk lebih terampil lagi. Oleh karena itu, untuk mendukung aktivitas siswa Tunarungu terdapat beberapa catatan bagi guru, penulis dan pengambil kebijakan diantaranya adalah: 
a. Bagi guru, sebelum melaksanakan kegiatan belajar di kelas diharapkan memahami kondisi kelas yang dijadikan ruang belajar siswa tunarungu. Guru juga disarankan menyiapkan rencana pembelajaran yang dimodifikasi dengan kebutuhan siswa tunarungu.

b. Bagi Kepala Sekolah selaku pengambil kebijakan. Adanya pendidikan inklusif di satuan pendidikan yang dilaksanakan, hendaknya secara rutin dilaksanakan kegiatan sharing atau pertemuan rutin bagi guru pendamping khusus dan guru mapel mengajar di kelas untuk saling berbagi pengalaman dan menggali informasi terkait kendala yang dihadapi di sekolah dan cara penyelesaian terbaik bagi jalannya proses pembelajaran yang ramah dan diiringi dengan kebijakan yang mendukung terselenggaranya pendidikan inklusif di sekolah.

c. Bagi orang tua, dengan bantuan orang tua di rumah saling memantau bersama guru mata pelajaran di sekolah agar bersama-sama (sejalan dalam) memahami siswa tunarungu dalam perkembangannya. Dengan ini mereka akan tumbuh menjadi anak yang mampu menghadapi masa depan dan lingkungannya.

d. Bagi pemangku kepentingan, dengan semakin banyaknya siswa tunarungu yang belajar di sekolah reguler maka pemerintah juga harus menyiapkan sumber daya manusia (SDM) yang menjadi pendamping khusus siswa tunarungu, menyediakan sarana dan prasarana yang mendukung dalam bentuk bantuan pada sekolah penyelenggara pendidikan inklusif. Memberikan peluang bagi guru untuk menerapkan berbagai strategi pembelajaran dengan menggunakan media kalkulator sebagai media pembelajaran yang selama ini tidak diizinkan digunakan pada saat siswa-siswa berkebutuhan khusus mengikuti ujian baik ulangan harian maupun ujian nasional. Dengan demikian, kebijakan pemerintah terkait hal tersebut dilaksanakan dengan memberikan rekomendasi untuk diizinkan secara tertulis bahwa siswa tunarungu dapat menggunakan media yang menjadi sarana belajar dan penanaman konsep khususnya matematika dalam menyelesaikan soal-soal ujian baik yang dilaksanakan oleh sekolah maupun Pemerintah sesuai karakter belajar siswa tunarungu.

\section{DAFTAR RUJUKAN}

Ahmadi, H.A. \& Supriyono, W. (2013). Psikologi Belajar Edisi Revisi. Jakarta: PT Rineka Cipta.

Booth, T. \& Ainscow, M. (2002). Index for Inclusion: Developing Learning and Participation in Schools. ERIC.

Dewayani, A. D. (2016). Model Pembelajaran Think Talk Write (Ttw) Terhadap Hasil Belajar pemecahan Soal Cerita Bilangan Bulat Matematika Siswa Tunarungu. Jurnal Pendidikan Khusus 8(1).

Fitriawan, R. (2016). Peningkatan Keterampilan Vokasional Melalui Pelatihan Cetak Sablon Kaos Bagi Anak Tunarungu Kelas XII di SLB Bakti Putra Ngawis. Widia Ortodidaktika 5(9): 895-907.

Hasan, S. A. \& Muryantinah, M.H. \& M Psych. (2014). Hubungan Antara Dukungan Sosial Teman Sebaya Dengan Penyesuaian Diri Siswa Tunarungu Di Sekolah Inklusi. Jurnal Psikologi Pendidikan dan Perkembangan 3(2): 128-35.

Hernadi, J. (2008). "Metoda Pembuktian dalam Matematika." Jurnal Pendidikan Matematika 2(1): $1-13$ 
Malatista, B. R, \& Eko S. (2012). Model Pembelajaran Matematika Untuk Siswa Kelas IV SDLB Penyandang Tunarungu \& Wicara dengan Metode Komtal Berbantuan Komputer. Jurnal Teknik Informatika dan Sistem Informasi 7(1).

Mansell, J. (2010). Raising Our Sights: Services for Adults with Profound Intellectual \& Multiple Disabilities. Department of Health, London.

Mardiana, L. (2016). Metode Multisensori Artikulasi Terhadap Kemampuan Membaca Menulis Huruf Al-Qur'an Permulaan dengan Model At-Tartil Jilid 1 Siswa Tunarungu. Jurnal Pendidikan Khusus 8(1).

Moores, D F. (2001). Educating the Deaf: Psychology, Principles, \& Practices. Houghton Mifflin Boston.

Nakken, H. \& Carla V. (2007). A Need for a Taxonomy for Profound Intellectual \& Multiple Disabilities. Journal of Policy \& Practice in Intellectual Disabilities 4(2): 83-87.

Patmawijayanti, I, D. (2016). Penggunaan Pendekatan Pembelajaran Berbasis Lingkungan untuk Meningkatkan Kosa Kata Anak Tuna Rungu Kelas 1 Sekolah Dasar Luar Biasa Mardi Mulyo Kretek Bantul. Widia Ortodidaktika 5(2): 121-32.

Poppes, P., Van der Putten, A.J.J \& Vlaskamp, C. (2010). Frequency \& Severity of Challenging Behaviour in People with Profound Intellectual \& Multiple Disabilities. Research in developmental disabilities 31(6): 1269-75.

Rahman, A., Farida A., \& Abdullah S. (2019). Pengembangan Media Video Bimbingan Konseling Untuk Mengurangi Perilaku Bullying. Jurnal Psikologi Pendidikan \& Konseling: Jurnal Kajian Psikologi Pendidikan \& Bimbingan Konseling 4(2): 129-36.

Ratumanan, T. G. \& Theresia L. (2016). Analisis Penguasaan Objek Matematika (Kajian Pada Lulusan SMA Di Provinsi Maluku). Jurnal Pendidikan Matematika Raflesia 1(2).

Salim, A. (2015). Pembelajaran Matematika Berbasis Komputer dengan Metode Multikomunikasi Untuk Siswa Kelas IV SDLB Penyandang Tuna Rungu \& Wicara. Jurnal Techno Nusa Mandiri 12(1): 77-95.

Slameto. (2010). Belajar \& Faktor-Faktor Yang Mempengaruhinya. Jakarta, Indonesia: PT Rineka Cipta.

Wahbi, A. \& Bey, A. (2017). Analisis Kesalahan Siswa dalam Menyelesaikan Soal Faktorisasi Suku Aljabar Ditinjau dari Objek Matematika pada Siswa Kelas VIII SMP Negeri 15 Kendari. Jurnal Penelitian Pendidikan Matematika 3(1): 17-30.

Weismann, I. Th. J., Ismail, T., \& Abdullah, S. (2018). The Development of Multicultural Based Cooperative Learning Model. The Social Sciences 13(1): 1-6.

Winarsih, M. (2007). Jakarta: Departemen Pendidikan \& Kebudayaan Intervensi Dini Bagi Anak Tunarungu Dalam Pemerolehan Bahasa.

Wuwungan, N. (2016). Peran Komunikasi Interpersonal Guru \& Siswa Tunarungu dalam Meningkatkan Sikap Kemandirian Anak Berkebutuhan Khusus di Sekolah Pembina Luar Biasa Provinsi Kalimantan Timur. eJournal Ilmu Komunikasi 4(4). 